\title{
Meninas do Ensino Médio: Quem quer estudar TI?
}

\author{
Jacques André Grings ${ }^{1}$, Naira Kaieski ${ }^{2}$, Paula Nunes ${ }^{2}$ \\ ${ }^{1}$ UNIPACS - Taquara, Rio Grande do Sul - Brazil \\ ${ }^{2}$ Instituto Federal de Educação Ciência e Tecnologia Sul-rio-grandense (IFSUL) \\ Sapiranga, Rio Grande do Sul - Brazil \\ jacques.grings@gmail.com, \{nairakaieski, paulanunes\}@ifsul.edu.br
}

Abstract. The paper examines a professional choice of young high school students, that are finishing this stage, in Paranhana/RS region. A survey with 1,328 students of both genders, aged between 15 and 20 years old, was applied, of which 734 (55\%) were girls. The answers indicate that these women mostly desire to attend Higher Education and that is really important the profession and the degree course, as well, in their personal achievement. However, careers and training related to technology presented a concern low demand.

Resumo. O artigo examina a escolha profissional das jovens concluintes do Ensino Médio da região do Paranhana/RS. Foi aplicada uma pesquisa com 1.328 alunos, de ambos os sexos, com idades entre 15 e 20 anos, sendo que 734 $(55 \%)$ eram meninas. As respostas indicam que essas, em sua maioria, desejam cursar o Ensino Superior e já escolheram tanto a profissão quanto o curso de graduação baseado na sua realização pessoal. Porém, carreiras e formações relacionadas com tecnologia apresentaram uma inquietante baixa demanda.

\section{Introdução}

Da fundação das primeiras escolas de Ensino Superior no Brasil, em 1808, até hoje, já se vão mais de dois séculos. Esse período ficou marcado na academia pela busca perenal de igualdade entre homens e mulheres. A priori, era permitida somente a presença do público masculino nos cursos, sendo que somente em 1879 foi autorizada a presença feminina nos cursos superiores [Brasil 1879].

Na contemporaneidade, a mulher ocupa lugar de destaque no Ensino Superior no Brasil. Dados divulgados pelo Instituto Nacional de Estudos e Pesquisas Educacionais Anísio Teixeira (Inep), referentes ao censo do Ensino Superior, indicam que o público feminino correspondeu a 55,6\% das matrículas em instituições de Ensino Superior no ano de 2016 [Inep 2017].

Porém, mesmo com todas as conquistas, a busca pela equidade ainda continua. Se no Ensino Superior existe predominância feminina, no mundo do trabalho a mulher ainda sofre discriminação. Pesquisa divulgada pelo Instituto Brasileiro de Geografia e Estatística (IBGE) atesta que as mulheres, em 2015, tiveram uma remuneração média 23,6\% menor do que os homens [IBGE 2017]. Nessa direção, escolher a profissão e consequentemente o curso superior pode ser um desafio ainda maior para as mulheres. É vital que esta decisão seja tomada por todos os jovens com consciência dos seus interesses e aptidões e total liberdade para priorizarem os seus valores pessoais [Figueiredo e Maciel 2016]. 
Os dados apresentados neste artigo são oriundos de uma pesquisa realizada com alunos concluintes do Ensino Médio da região do Paranhana no estado do Rio Grande do Sul (RS). Os questionamentos buscaram evidenciar a escolha da profissão, do curso superior e da instituição de ensino e suas motivações. Para este ensaio são apresentados apenas os resultados obtidos com as respostas do público feminino com foco especial nas escolhas relacionadas com a área das ciências exatas e da terra e com profissões e cursos ligados à Tecnologia da Informação (TI).

\section{Metodologia}

O estudo foi realizado na região do Paranhana/RS, entre os meses de outubro e novembro de 2016, com os alunos concluintes do Ensino Médio. A região é formada pelos municípios de Parobé, Taquara, Igrejinha, Três Coroas, Rolante e Riozinho, totalizando uma população de 185.468 habitantes segundo o censo demográfico realizado pelo IBGE em 2010 [IBGE 2011]. Destaca-se economicamente na região do Paranhana, referente ao Valor Adicionado Bruto (VAB), os setores de serviços e a indústria de transformação com especial destaque para o segmento de couro/calçados e alimentos [Bertê et al. 2015].

Na região, existe um total de 18 escolas de Ensino Médio, sendo uma municipal, 3 particulares e 14 estaduais. A pesquisa foi aplicada com todas as turmas concluintes totalizando 1.328 respostas. A Figura 1 ilustra o público alvo separado por gênero e tipo de escola.

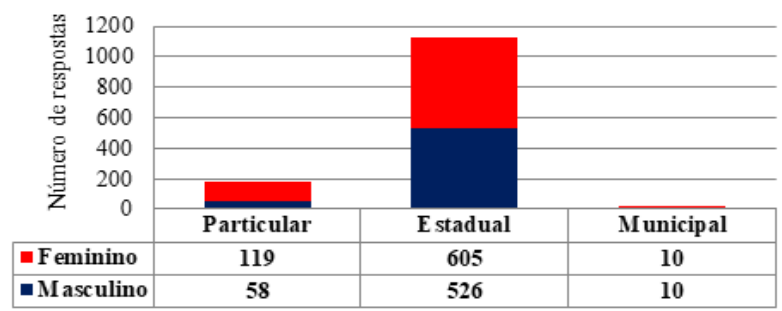

Figura 1. Gênero x Tipo de escola

Como instrumento para a coleta de dados, foi utilizado um questionário estruturado, contendo 9 perguntas abertas e fechadas ${ }^{1}$. O objetivo da pesquisa foi averiguar, de forma geral, os fatores que influenciam os jovens formandos do Ensino Médio da região tanto na escolha profissional quanto do curso superior e da instituição de ensino. Após a coleta, os dados foram registrados e analisados em uma planilha eletrônica de maneira que se tornasse possível fazer as correlações desejadas. É relevante citar que a pesquisa foi realizada a posteriori das visitas que os alunos fazem anualmente às Instituições de Ensino Superior da região e outras próximas, para conhecer os cursos ofertados.

\section{Análise e discussão dos dados}

Para este artigo foram avaliadas exclusivamente as respostas do público feminino que participou da pesquisa. Com especial interesse nas escolhas por profissões e cursos de graduação relacionados com a área das ciências exatas, mais especificamente com TI.

Foram obtidas 734 respostas, sendo que 88,4\% eram jovens com idade entre 17 e 18 anos. Observou-se que praticamente $80 \%$ das entrevistadas relataram já ter

\footnotetext{
${ }^{1} \mathrm{O}$ instrumento de pesquisa utilizado pode ser acessado através do endereço https://goo.gl/L6LeYs
} 
escolhido a profissão que deseja seguir na vida adulta, $10 \%$ informaram não ter decido e outros $10 \%$ responderam estar indecisas. Quanto à escolha profissional, um fato interessante foi a diversidade de carreiras citadas, 65 no total. Isso pode estar demonstrando, por um lado, a variedade de desejos profissionais das alunas, por outro, refletindo a diversidade de cursos ofertados.

É necessário considerar que embora as jovens tenham relatado já ter escolhido uma profissão, muitas vezes acabam mudando de ideia ao ingressar no Ensino Superior ou no mercado de trabalho. Torna-se importante grifar que em termos de profissão foram citadas apenas duas diretamente relacionadas com TIC: analista de sistemas e desenvolvedora de jogos, totalizando assim apenas três futuras profissionais ingressando na área de computação.

Outro ponto importante da pesquisa se refere a decisão de cursar uma graduação e a definição do curso a ser frequentado no Ensino Superior. A Figura 2 apresenta o percentual de alunas que desejam cursar o Ensino Superior e, destas, aquelas que já definiram o curso de graduação.

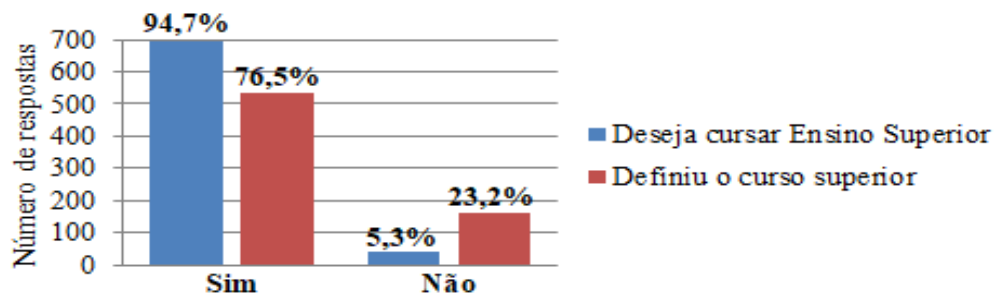

Figura 2. Desejo de cursar o Ensino Superior em relação a escolha do curso

Analisando a Figura 2, percebe-se que mais de 94\% das alunas demonstraram interesse em cursar a faculdade. A partir desses dados, é possível inferir que a maioria das jovens reconhece o Ensino Superior como um caminho natural para o seu desenvolvimento, tanto pessoal quanto profissional. Contudo, "apenas" $76,5 \%$ das jovens afirmaram já ter feito a escolha do curso superior.

No que concerne à dúvida, passa a ser natural esse sentimento entre os jovens, geralmente na definição da formação superior, haja vista que um mesmo curso abre diversas possibilidades para diferentes profissões. No total foram elencadas 56 opções de formação distintas e para facilitar a compreensão deste dado, os cursos citados foram agrupados segundo a tabela de áreas do conhecimento estabelecida pela Coordenação de Aperfeiçoamento de Pessoal de Nível Superior (CAPES). Baseado nesta tabela existe 4 níveis de separação, porém foi utilizado apenas o primeiro nível, denominado "Grande Área" que representa a "aglomeração de diversas áreas do conhecimento, em virtude da afinidade de seus objetos, métodos cognitivos e recursos instrumentais" [CAPES 2017].

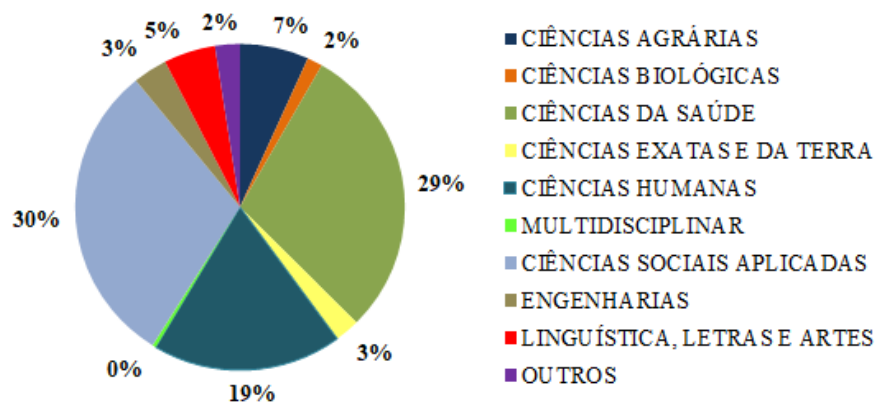

Figura 3. Grandes áreas do conhecimento 
A Figura 3 apresenta as escolhas de cursos de graduação do público feminino pesquisado segundo as grandes áreas definidas pela CAPES. As três áreas com maior público, são ciências sociais aplicadas, ciências da saúde e ciências humanas. Já formações relacionadas com ciências exatas e da terra representam a escolha de apenas $3 \%$ das mulheres que participaram da pesquisa.

\section{Ponderações finais}

No presente estudo, buscou-se examinar as escolhas profissionais das jovens concluintes do Ensino Médio da região do Paranhana/RS. Não foi objeto dessa pesquisa investigar os motivos que levam as meninas a não escolherem profissões e cursos relacionados com tecnologia, porém cabe apontar que apenas três jovens de um total de 734 almejam profissões e cursos de graduação nessa área. O que pode ajudar a explicar esse desinteresse das meninas são as especificidades regionais, haja vista que a região possui uma economia predominante industrial, ofertando dessa forma poucas vagas na área de TIC ou mesmo informações sobre esta carreira.

É relevante citar que a realização pessoal foi o fator preponderante apontado tanto para a escolha profissional $(39,7 \%)$ quanto para a formação superior $(85 \%)$. Os aspectos pessoais não podem ser ignorados quando decisões sobre o futuro de um indivíduo são tomadas. Contudo, é importante estimular a presença feminina em áreas de pesquisa e atuação onde tradicionalmente são minoria. Tal fato estimula a diversidade intelectual e impulsiona o setor com uma maior força de ação.

A falta de interesse das jovens pesquisadas pela área de ciências exatas e da terra, mais especificamente tecnologia, é preocupante. Contudo, não se pode negligenciar o fato de que as mulheres reconhecem o Ensino Superior como um caminho natural para o seu próprio desenvolvimento, pois a maioria deseja graduar-se. Uma grande variedade de profissões e cursos foi citada pelas participantes da pesquisa como desejo de carreira. Esta pluralidade pode ser benéfica ao ponto de subsidiar uma economia regional mais sustentável e resiliente, mas também soturna, por mascarar a indecisão e os sonhos pueris que permeiam os jovens.

\section{Referências}

Bertê, A. M. A. et al. (2015) "Perfil socioeconômico: COREDE Paranhana Encosta da Serra". Secretaria do Planejamento, Mobilidade e Desenvolvimento Regional, Governo do Estado do Rio Grande do Sul, Porto Alegre.

Brasil. (1879) Decreto n. 7.247, de 19 de abril de 1879. Rio de Janeiro.

CAPES (2017) "Tabela de Áreas de Conhecimento/Avaliação". Disponível em: $<$ http://www.capes.gov.br/avaliacao/instrumentos-de-apoio/tabela-de-areas-doconhecimento-avaliacao>. Acesso em: $15 \mathrm{fev} 2018$.

Figueiredo, K. da S. e Maciel, C. (2016) "Reflexões sobre Gêneros, Tecnologia e Processo Vocacional", In: Anais of Women in Information Technology (WIT) XXXVI Congresso da Sociedade Brasileira de Computação, Porto Alegre, Brasil.

IBGE (2011) “Sinopse do Censo Demográfico 2010”, IBGE, Rio de Janeiro.

IBGE (2017) "Estatísticas do cadastro central de empresas", IBGE, Rio de Janeiro.

Inep (2017) “Censo da educação superior 2016: Principais resultados", Diretoria de Estatísticas Educacionais. 